Communication

\title{
Child Life Specialists in Pediatric Hospital Care
}

Kokila Jeyamurugan $\mathrm{MD}^{*}$, Ratna B Basak MD, FRCPCH

Department of Pediatrics, Brookdale University Hospital Medical Centre, Brooklyn, NY, USA; EMails: kjeyamur@bhmcny.org; ratnabimalbasak@gmail.com

* Correspondence: Kokila Jeyamurugan; E-Mail: kjeyamur@bhmcny.org

Academic Editor: Leila Kozak

Special Issue: Integrative Therapies in Palliative Care

OBM Integrative and Complementary Medicine 2020, volume 5 , issue 3

doi:10.21926/obm.icm.2003034
Received: May 12, 2020

Accepted: July 15, 2020

Published: July 17, 2020

\begin{abstract}
Child life specialists (CLS) are trained providers who form part of a pediatric multidisciplinary and pediatric palliative care team. Their role is invaluable to mitigate the stress and anxiety of children during hospitalization. They may use various strategies in children like play, art and music therapy and pet therapy, to help self-express and cope with painful procedures. We present a brief narrative on CLS with a case of a 10- year- old Hispanic boy who had metastatic osteosarcoma.

The case illustration is from a prior institute that one of the coauthors was associated with.
\end{abstract}

\section{Key words}

Pet therapy; child life specialist; pediatric palliative care

\section{Introduction}

In the United States, more than 500,000 children are coping with life-threatening conditions every year [1]. Many of them are admitted for acute conditions, and a few for end of life care. 
Hospitalization in children is a great source of stress; they are not only deprived of their familiar and comforting environment, but may have to undergo various painful procedures and treatments leading to significant physical and emotional distress [2]. Pediatric palliative care consults help in mitigating many such issues to provide good experiences during these times.

Pediatric Palliative care has an integrated interdisciplinary approach, with the goal of enhancing the quality of life, minimizing the suffering of children and their families facing serious illnesses by embracing the physical, emotional, psychosocial and spiritual elements [3]. Palliative care should be initiated when a serious illness is diagnosed and continued throughout the course, regardless of the outcome [3]. The members of the palliative team may vary in hospitals and usually include physicians, nurse practitioners, nurses, social workers, chaplains, bereavement coordinators and child life specialists (CLS) [4]. Most pediatric hospitals across United States have child life specialists with a commonly accepted standard ratio of 1 CLS to 15 patients. However, the staffing may be individualized based on the severity and acuity of illness of the patients served [5].

CLS are professionals who undergo training and develop expertise in helping children and their families cope with the stress and challenge during an illness needing hospitalization [6]. Armed with a background in child development, psychology, and counselling, CLS work closely with children and families in medical settings, help them navigate through the challenges of hospitalization, offer emotional support, educate and prepare children using age appropriate strategies to better understand a medical event or procedure. They collaborate with parents and the palliative care team to meet the distinct needs of the patient in a family centered model of care $[5,7]$. CLS engage themselves in a variety of hospital settings, such as inpatient units, ambulatory clinics, intensive care units, emergency departments and at times in homes of terminally sick children [5, 7]. Apart from providing developmentally appropriate therapeutic play strategies like music, art and reading activities to help reduce anxiety and improve coping skills, additional novel programs like animal assisted therapy and therapeutic clowning are now being employed for pediatric patients of all ages [5].

The story of CLS began early in the 1920s when early child life professionals were identified as "play ladies" as they considered play as a means to promote optimal development and minimize the adverse effects of hospitalization for children and their families [8]. Today the field has grown exponentially and has proven to be an excellent career choice [6]. The requirements of a certified child life specialist (CCLS), include a minimum of a bachelor's degree in child life, child development or a closely related field, with a successful completion of a 480 to 600 hours of child life internship under the direct supervision of a CCLS and passing the child life professional certification examination [5].

A recent research on parental perception of CLS revealed that most parents had no prior knowledge of the role of CLS but were highly satisfied with their experience with them [9]. Another scholarly article found that child-life interventions had a positive effect on family and staff satisfaction and enhanced the child's perception of pain and distress [10].

We present a case that emphasize the role of CLS in assisting the pediatric and palliative care team to manage a child with life limiting illness by employing animal assisted (pet) therapy. 


\section{Case Description}

We describe a case seen by one of the coauthors at an institution with past affiliation. A 10year old boy diagnosed with metastatic osteosarcoma which had spread to his lungs, bones and liver was admitted for yet another round of chemotherapy and pain management. The parents were from Dominican Republic and knew little English. The child was always quiet and avoided all interactions with the providers. It was difficult to understand how much the family knew about his prognosis. It was also impossible to gauge what the child knew about his illness and if the parents wanted him to know of his terminal condition.

The CLS used several strategies to bridge the gap. They deployed a CLS working in an outpatient setting who was fluent in Spanish to visit the family every day. The CLS was able to build a rapport and identify that the patient had a pet dog back home who he was very attached with. She contacted an organization which specializes in pet therapy. Soon a pet dog was brought to the hospital to visit our patient every day. The child's transition was dramatic - he became more interactive and social, appeared relaxed and even took part in the medical clown show. The pet visit helped reduce his anxiety and boosted his mood and appetite. He appeared to be more receptive to treatment and ready to take part in his care. It allowed the child and family to relax and bond with each other. The positive response in child's behavior gave a sense of relief and satisfaction to the parents. It was an opportunity to temporarily escape the medical decisions and procedures. Perhaps, 'Pet therapy [2]' allowed him to express his love for animals and this became a source of comfort for the patient and the family during his final days.

CLSs made every effort to build a good rapport and trust with the patient and the family. After assessing the patient and the family's needs and coping skills, CLSs worked with other team members to provide support for the plan of care. The factors that had an influence on optimizing the quality of life such as patient's temperament, coping and cognitive abilities, parental anxiety and involvement were considered. Interpreter services were used as appropriate to overcome language barrier and ensure effective communication with the family facilitating family-centered care model [5].

CLSs helped in normalizing the hospital environment for our patient, making it appear as friendly and comfortable as possible. The child's favorite articles from home were left in his room, especially his blanket, favorite toy and his own pajamas. His hospital room walls were decorated with posters and photographs of family members that made him feel happy and at home. In addition to working with our patient, CLSs encouraged support for the family. Through appropriate communication they made parents and siblings understand their responsibilities and roles. They engaged the parents in the care of the child and gave them guidance on helping the child during treatments and procedures. This helped our patient feel less anxious and he was able to cope more effectively. CLSs used play therapy because it allowed the child to express himself and use his imaginations, which provided opportunities to learn, explore and better understand the feelings and the environments around them [11]. They also helped our patient to maintain relationships and feel connected with his peers through regular video calls. These interventions indeed, helped the child to get well adapted to the hospital environment. Family activities like 'Friday movie nights' were encouraged to have sense of normal life in the hospital setting. CLSs encouraged sibling support, allowing them to visit when possible and spend some time creating art, reading books and having fun together. CLSs prepared the siblings to acknowledge the 
changes they can note in the appearance and behavior of the child which helped in decreasing anxiety by addressing their concerns and preparing them for the future including end-of-life situations $[11,12]$. Debriefing with the medical team was done routinely to keep all the members of the team informed about the goals of care and help the team cope with the impending loss.

Finally, CLSs spent time with the child making legacy craft items such as cast molds, scrapbooks, fingerprint charms and videos. These crafts were made by the child for their loved ones to make memories and have their legacy carried forward [8, 12].

CLSs created a supporting and trusting environment for the family. During the final days, they provided emotional support and bereavement care to overcome the painful experience. Siblings were given the opportunity to express their feelings. They attended the funeral and were assured that their feelings will change over time [6]. The parents appreciated the support and the compassionate and consistent care offered by the CLS to make the end of life experience a bearable one.

\section{Comment}

This case highlights the important role of CLS as an integral member of palliative care team. CLS recognize individuality in a child and provide developmentally appropriate activities based on one's self-directed interest, to help cope with medical experiences [5, 7].

The ways by which young children cope with stress vary with that of adults. Children between the ages 10-12 use regression, withdrawal, acting out or feeling guilty which were all found in our patient. Adolescents use defense mechanisms or uncooperative behavior to combat stressors [13]. This can have a negative impact on the parents and siblings affecting their physical and psychological wellbeing [14].

CLSs serve as advocates for addressing the special needs of children and families. They help to increase the child's cooperation and comfort by preparing and describing to them in a child friendly language before any procedure and treatment. The involvement and presence of family members around positively impacts the child's adjustment to the health care experience [11].

Play is an important aspect of child life program. It provides an opportunity for parental and sibling engagement. CLSs also offer sibling support, provide space for discussion of their feelings and allow them to spend quality time with the sick child whenever possible [5].

CLSs play a vital role in preparing family members for anticipated death of the child in end-of life circumstances. They help foster family-centered pediatric palliative care, from including the child and family in legacy making to providing grief counseling [5].

Pet therapy is one of the multiple coping techniques that CLSs use to help children deal with traumatic experiences.

Pet therapy serves to improve physical and mental wellbeing, increases social interaction and provides a sense of self-esteem and independence in children [15]. A pilot project on animal assisted therapy in pediatric oncology found that dog visits helped to reduce the stress and anxiety in hospitalized children and increased treatment receptivity [2]. While dogs and cats were the most common animals used in pet therapy, other animals including horses, guinea pigs, birds and fish are also used. The animal's type and natural behavior will determine where it will be helpful [16]. Dogs of any breed, size, or age may qualify to become a therapy animal provided they 
possess certain traits - calm temperament, non-aggressive, patient, friendly and receptive to training [17].

In the United States, pet therapy began in 1919 when dogs were used to treat psychiatric patients. Dr. Boris Levinson, an American child psychiatrist was the first to document the positive impact of using pets in child care practice. Since then, animal therapy has been extensively used as a therapeutic tool in many countries [18]. Pet therapy or Animal assisted therapy is a novel approach that has become available in many medical centers and provide hospitalized children, the opportunity to interact with visiting pets or animals that are raised in the medical setting [15].

Despite the benefits, some reasonable concerns of pet therapy include allergic reactions, chances of infection from animals, animal bites and other untoward pet behaviors. However, therapy animals should be clean, well trained and housebroken, screened medically and fully vaccinated [15].

Although the field of child life is rapidly developing in the United States, awareness about child life programs and the function and responsibilities of CLSs in children's hospitals is still very limited. While health care professionals may be aware of child life, they often lack a comprehensive understanding of the educational and training needs, the services they provide and their role in the interdisciplinary health care team [19]. While future research is required to illustrate the importance of the contributions of child-life specialists to the pediatric palliative care team, it remains essential that child-life programs continue to grow and adapt to the evolving health care environment and provide the best possible quality of care for children and their families $[5,20]$.

\section{Conclusion}

Our patient's end of life experience was powerfully impacted by enriching and improving the quality as a result of coordinated approach and involvement of the CLS. They should be considered as an essential member of pediatric and pediatric palliative care teams, and their work should be integrated into the plan of care to ensure the best outcome.

\section{Author Contributions}

Dr. Jeyamurugan has designed, analyzed, drafted the manuscript and approved the final version of the manuscript. Dr. Basak has conceptualized, designed, analyzed, drafted the manuscript and approved the final version of the manuscript.

\section{Competing Interests}

The authors have declared that no competing interests exist.

\section{References}

1. Huang IC, Wen PS, Revicki DA, Shenkman EA. Quality of life measurement for children with life-threatening conditions: Limitations and a new framework. Child Indic Res. 2011; 4: 145-160.

2. Bouchard F, Landry M, Belles-Isles M, Gagnon J. A magical dream: A pilot project in animalassisted therapy in pediatric oncology. Can Oncol Nurs J. 2004; 14: 14-17. 
3. Committee on Bioethics. Palliative care for children. Pediatrics. 2000, 106: 351-357

4. Linebarger J, Moreno MA. Pediatric palliative care. JAMA Pediatr. 2019; 173: 1115.

5. Committee on Hospital Care and Child Life Council. Child life Services. Pediatrics. 2014, 133: e1471-e1478.

6. Home - Association of Child Life Professionals. Arlington: The Association of Child Life Professionals; 2020 [cited date 2020 April]. Available from: https://www.childlife.org/.

7. Child life specialist. Wikipedia, The Free Encyclopedia; 2020 [cited date 2020 April]. Available from: https://en.wikipedia.org/wiki/Child life_specialist.

8. Beickert K, Mora K. Transforming the pediatric experience: The story of child life. Pediatr Ann. 2017; 46: e345-e351.

9. LeBlanc CK, Naugler K, Morrison K, Parker JA, Chambers CT. Parent perceptions and satisfaction with inpatient child life specialist interventions and the role of child temperament. Child Health Care. 2014; 43: 253-272.

10. Tyson ME, Bohl DD, Blickman JG. A randomized controlled trial: Child life services in pediatric imaging. Pediatr Radiol. 2014; 44: 1426-1432.

11. Goodhue K. Child life at end of life: Providing child life services in a pediatric home hospice setting. Child Life Council Bulletin Spring. 2016; 34: 6-26.

12. What is Pediatric Palliative care? New York: Center to Advance Palliative Care; 2017 [cited date 2020 April]. Available from: https://getpalliativecare.org/whatis/pediatric/.

13. Krupnick JL. CHAPTER 5, Bereavement During Childhood and Adolescence. Bereavement: Reactions, consequences, and care. Washington (DC): National Academies Press; 1984. Available from: https://www.ncbi.nlm.nih.gov/books/NBK217849/.

14. Wittenberg E, Saada A, Prosser LA. How illness affects family members: A qualitative interview survey. Patient. 2013; 6: 257-268.

15. Donowitz LG. Pet therapy. Pediatr Infect Dis J. 2002; 21: 64-66

16. Pet therapy. San Francisco: Healthline Media; 2020 [cited date 2020 May]. Available from: https://www.healthline.com/health/pet-therapy.

17. Therapy dogs and animal-assisted therapy. New York: The Spruce Pets; 2019 [cited date 2020 May]. Available from: https://www.thesprucepets.com/therapy-dogs-and-animal-assistedtherapy-1118680.

18. Hooker SD, Freeman LH, Stewart P. Pet therapy research: A historical review. Holist Nurs Pract. 2002; 16: 17-23.

19. Lookabaugh S, Ballard SM. The scope and future direction of child life. J Child Fam Stud. 2018; 27: 1721-1731. 
OBM Integrative and Complementary Medicine 2020; 5(3), doi:10.21926/obm.icm.2003034

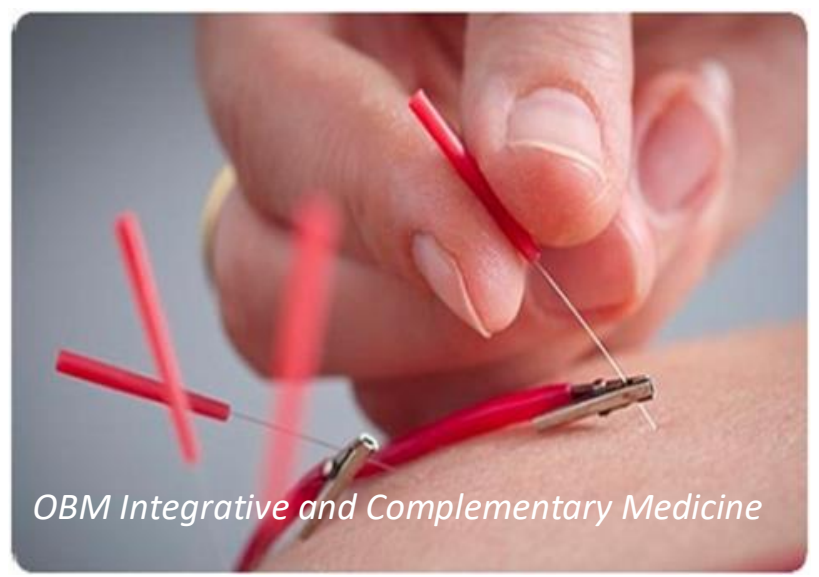

Enjoy OBM Integrative and Complementary Medicine by:

1. Submitting a manuscript

2. Joining in volunteer reviewer bank

3. Joining Editorial Board

4. Guest editing a special issue

For more details, please visit:

http://www.lidsen.com/journals/icm 